\title{
Land change-based forest management scenario in the typology of island clusters in Maluku Province, Indonesia
}

\author{
PATRICH PHILL EDRICH PAPILAYA ${ }^{1, \bullet}$, I NENGAH SURATI JAYA ${ }^{2}$, TEDDY RUSOLONO ${ }^{2}$, \\ NINING PUSPANINGSIH ${ }^{2}$ \\ ${ }^{1}$ Program of Forestry, Faculty of Forestry and Environment, Institut Pertanian Bogor. Jl. Lingkar Akademik, Kampus IPB Dramaga, Bogor 16680, West \\ Java, Indonesia. Tel.: +62-251-8621677, Fax.: +62-251-8621256, `email: patrichp@yahoo.com \\ ${ }^{2}$ Department of Forest Management, Faculty Forestry and Environment, Institut Pertanian Bogor. Jl. Lingkar Akademik, Kampus IPB Dramaga, Bogor \\ 16680, West Java, Indonesia
}

Manuscript received: 1 March 2021. Revision accepted: 20 August 2021.

\begin{abstract}
Papilaya PPE, Jaya INS, Rusolono T, Puspaningsih N. 2021. Land change-based forest management scenario in the typology of island clusters in Maluku Province, Indonesia. Biodiversitas 22: 3756-3763. This study aims to describe the development of forest area utilization scenarios with biophysical, social and spatial trend approaches. In this study, spatial trends were identified using forest and land cover maps from 2000 to 2018, and the methods used include change detection, spatial trend and overlay. The study was designed using forest cover scenarios along with spatial trends and social and biophysical approaches. The results of the 5 typologies of island clusters analysis showed that forest degradation has occurred in an area of \pm 77102 ha between 2000 and 2018 with an a verage of 4283.4 ha/year. Furthermore, Total Land Cover Loss at the location of the five island cluster typology for 18 years was found to be \pm $422805 \mathrm{Ha}$ with an average of $\pm 23489.06 \mathrm{ha}$ /year. The land capability was categorized into 3 classes. Therefore, the five spatial trends were known to form in the typology of five island clusters with different directions and magnitudes.
\end{abstract}

Keywords: Change Analysis, Land Capability, Spatial Trend, Typology.

\section{INTRODUCTION}

One-quarter of forest areas worldwide are maintained for extensive management purposes (FAO 2015; Köhl et al. 2015). Meanwhile, the type of practice and intensity of management depend on activities that transform the forest into various conditions and increase sustainability issues (Lindenmayer et al. 2012, Stanturf et al. 2014, Köhl et al. 2015). To reduce the impact of natural forest change by management activities and promote the principle of sustainability, sustainable forest management has been widely implemented in the past quarter of a century (Mori 2011; Gibson 2018; Oettel and Lapin 2021).

Forest planning has focused more on the technical aspects of using conventional and modern technology to facilitate achievement of forest management goals. Meanwhile, various silviculture techniques such as the application of advanced technology in environmentally friendly harvesting activities and the application of remote sensing technology have been applied to achieve sustainable forest management. However, this has not been able to prevent the forest from continuous degradation over time (Tudoran and Zotta 2020; Pascual 2021).

The Maluku Provincial government has set a strategy to accelerating development by establishing strategic areas called Island Clusters (Bappeda 2013). This area is formed based on geographical proximity, cultural similarity, natural resource potential, economic similarity, and economic orientation. The establishment of this Island Cluster is a solution to accelerate the development process in all sectors. As an archipelagic province, the planned management for small islands is undeniable because they have a high vulnerability viz. from i) global processes such as climate change causing an increase in sea level, ii) regional processes which include pollution from urban developments near small islands, and iii) local processes such as environmental degradation of the environment and resources due to population growth (Farhan and Lim 2011).

Forest is very important on small islands because it serves as a regulator of the supply of water resources, namely, as a source of clean water, irrigation, and forest industry as natural resources that have ecologically, economically, and socio-cultural benefits for residents. Meanwhile, the population growth rate and utilization of forest resources on small islands are essential to avoid the degradation of available natural resources.

Remote sensing technology and geographic information systems (GIS) are widely used and recognized as sophisticated and useful tools in detecting land use and cover changes (Kazemi and Akinci 2018; Mazahreh et al. 2019; AL-Taani et al. 2021). Moreover, predicting future land use and cover changes is useful for development planning and better management of natural resources (Khawaldah 2016). Therefore, this study uses spatial trend analysis to predict land-use changes, specifically in island clusters of Maluku Province using 20 years of forest cover data.

This study aims to develop guidelines for forest areas management based on spatial trends and land capability classes. The specific objectives for this study were as 
follows: 1) identification of the rate of land-use change from 2000 to 2018,2 ) the establishment of land capability classes, and 3) the formation of spatial trends in each island group.

\section{MATERIALS AND METHODS}

\section{Location and Time of Study}

The fieldwork part of this study was conducted from September to December 2020 in Maluku Province, on the twelve Island Clusters set by the regional government of the province. The location of the study area is shown in Figure 1.

\section{Materials}

ArcGis ver. 10.8 was used to perform various spatial analyses such as extraction of forest cover data from district to sub-district level and conversion of shapefile (*.shp) format to TerrSet. Meanwhile, the statistical package for the social sciences (SPSS) ver. 25 and Minitab ver. 19.4 were used to generate five island cluster typologies through discriminant and cluster analysis. The Land Changes Modular (LCM) facility from TerrSet 2020 Geospatial Monitoring and Modeling was used to create land and forest management scenarios. The LCM analyzed the land cover change in the time-series data, empirically model its relationship with explanatory variables, and project future changes in form of decision-making scenarios (Eastman 2020). Furthermore, MS Word was used to compile reports of study results, while the Lenovo Ideapad 720S-141KB laptop was used to collect data and compile the reports

\section{Data Collection Technique}

The basis for this study is biophysical, social, and economic data from 118 sub-districts in twelve island clusters of Maluku Province in 2018. Meanwhile, shapefile data of district, city, and sub-district boundaries of Maluku Province, Forest Land Cover of 2000, 2009, 2018, and Forest Areas of 2018 were derived from the Ministry of Environment and Forestry (KLH). Furthermore, the Landsat image from 2000 to 2020 was downloaded from the https://earthexplorer.usgs.gov/.

Land Capability Analysis of island clusters uses a series of data, including rainfall, soil type, geology, slope, elevation, watershed map, land cover, and geographical boundaries coordinate of districts and regencies in Maluku Province. The data from the discussions with the Regional Leaders of the province and the report on the development direction of Maluku Island-Based Development were used as additional data in this study.
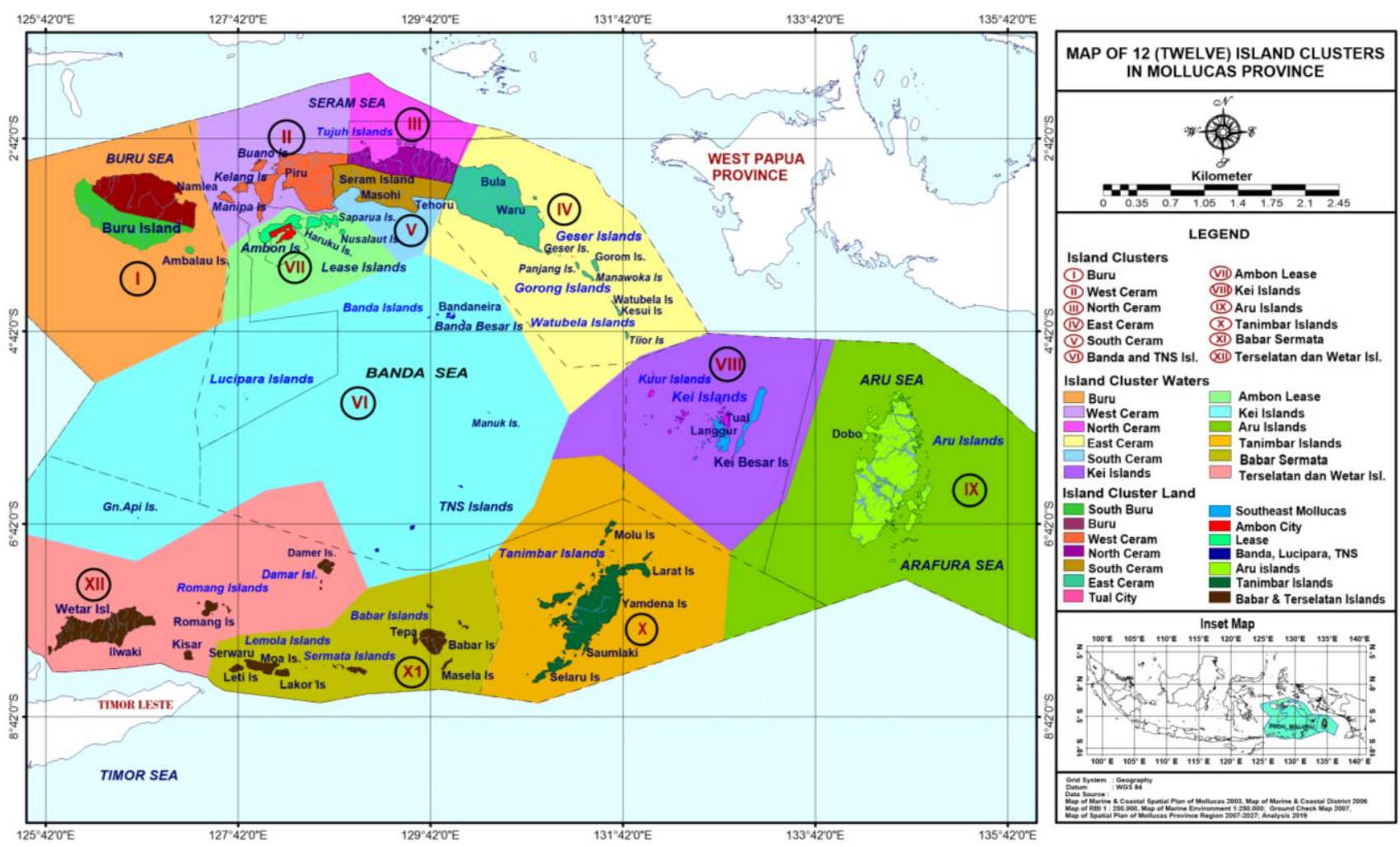

Figure 1. Research site map in Maluku Province, Indonesia 


\section{Data analysis \\ Land Change Modeler}

Land Changes Modeler (LCM) is a spatial data processing facility from TerrSet Geospatial Monitoring and Modeling System 2020. The LCM analyzes changes in land cover in form of time-series data that empirically model its relationship with explanatory variables and projects future changes in form of decision-making scenarios (Tarawally et al. 2019; Eastman 2020). Moreover, LCM is built from several sub-menus which include 1) Change analysis: analysis of land changes in the past, 2) Transition potentials: modeling potential of land transitions, 3) Change prediction: which projects the future direction of land change, 4) Planning: Evaluating planning interventions, and 5) REDD Project: Estimated Gas Emissions from REDD projects. Furthermore, LCM facilities 1-3 are used to analyze land cover changes and the direction of change.

The change analysis facility provides a set of tools to access land cover change speed and allows evaluating gains together with losses. These tools provide four facilities, namely project parameters, change analysis, change maps, and spatial trend of change, that are used to create forest management scenarios from time-series analysis of forest land cover from 2000 to 2018.

\section{Spatial trend}

The spatial trend tends to change with space, meanwhile, Zekâi (2017), described the trend as a pattern in which some events develop as changes that increase (up) or decrease (downwards). Each trend has a general direction expressed in terms of encouragement, inclination, shift, and others that depend on its use. Moreover, spatial trends are represented as systematic changes in color from top to bottom plot analysis with special. Chen et al. 2011, stated that spatial trend is used to describe the specific movement of species in climate change. In this study, the term trend focuses on quantitative and qualitative changes. Moreover, quantitative means a broad-scale change, while qualitative is indicated by a change in the color of the object of this study. Meanwhile, the spatial trend was obtained by analyzing land cover change data from 2000 and 2018 using Idrisi TerrSet 2020. These include changes in forest land cover into several types of land cover such as forest to non-forest (agricultural areas, built-up land, open areas and non-productive areas).

\section{Land capability analysis}

Land use is linked to human activities that are directly related to the land which regulates the use and existing resources and causes impacts on land (Baja 2012). Moreover, land capability classification is defined as a land grouping system based on its ability to produce general cultivation crops and sustainable grazing plants over a long period (Atalay 2016). Meanwhile, optimization of land use plans and different allocation methods have been developed (Zhang et al. 2012). The Geographic Information Systems (GIS) that is used for proposed analysis, models dynamic management changes through environmental, natural, social, political and economic data integration (Bottero et al. 2013; Veldkamp and Lambin 2001). One of the achievements in this field was carried out by Rocha and Kurtz (2001).

The land capability analysis aims to examine its capability in forest areas and island clusters. Meanwhile, the analysis method follows the regulation of the Minister of Public Works No.20/PRT/M.2007 on guidelines for physical and environmental, economic, and socio-cultural analysis techniques in the preparation of Spatial and Regional Planning. This method is modified with the general physical assessment rules of the forest environment. The value of land capability was based on the analysis of land capability units (SKL) with modifications. Furthermore, the land capability unit (SKL) uses six land units, namely, morphological, slope stability, water availability, drainage, land against erosion, and ease in the work. From all units of this land overlap (overlay), the result gives the class of land capability from 1 to 5 . In this study, the capability class was divided into high, medium and low.

All data analysis ranging from the discriminant, cluster, land cover changes, and capability class determination together with the spatial trend were carried out at the remote sensing laboratory of the Faculty of Forestry, IPB University.

\section{RESULTS AND DISCUSSION}

\section{Land capability}

Land is a renewable resource that serves as the basis for human survival and development, by providing raw materials and a guaranteed space for development (Sun et al. 2018). This is influenced by the growth of the built-up region and the consequences of human activity, leading to degradation and loss of ecosystem services (Zari 2014). Therefore, land capability assessment becomes a fundamental need to create the sustainability of natural resources.

The land capability of the 5 Island Cluster Typologies was made based on the overlay of 6 maps of the land capability unit (SKL). The results give different values showing that the area with high capability to be in Typology 1, 2 and 5, with the following ability class areas, namely, Typology 1 covering an area of 1,042,656.86 ha, Typology 2 with 157780.63 ha, and 5 with 108,964.53 ha. Furthermore, the area with the highest capability class was in two regencies, namely Aru and Southwest Maluku, followed by part of North and East Seram Regency. Generally, land capability classes in 5 the typologies of the island showed that Land Capability ranges from high to low classes, where the class covers an area of 1708163.95 $(38.07 \%)$, medium covers 1469089.25 (32.74\%), and the high covers 1309402.02 (29.18\%). However, the typology of island clusters 3 and 4 have only high and medium classes. The Land Capability Class as shown in Table 1 indicates a unique result when observed as a distribution following the Island Group Typology. This high land capability class showed that when the cluster area's scope was small, the area of this class dominated. The Typology 
Cluster 4 had a total area of 210550.75 ha (4.69\%) while the high low land capability class was $72.13 \%$. This was similar to The Typology of Island Clusters 2 and 3, where the medium class shows different results from the ability class. Meanwhile, Table 1 shows that this ability class area was evenly distributed in each Typology of the Island Cluster and its distribution was shown in Figure 2.

Meanwhile, the low ability class refers to the condition of land that has a high limiting factor. This class was dominated spatially from moderate to heavy topography, with high rainfall and difficult to manage for agricultural purposes. Moreover, improper planning of this area triggers land degradation in the latter days, therefore, the right usage is for protection and conservation, assuming it is used as a production forest. Therefore, there is a need for strict regulation and a forest management system to encourage sustainability by minimizing the impact of environmental damage.

The medium ability class has a relatively large area of $32.74 \%$ (1469089.25 ha) of the total typology area. This class was found to be s ideal for forestry and agricultural activities due to its physical condition and a cordial climate. This area was on a moderate to heavy topography with mild to high rainfall. Forest business activities certainly follow the rules of an environmentally friendly silviculture system. This Medium Capability Class was almost evenly distributed in 5 typologies of the island group. Therefore, this class is targeted for forestry and nonforest development such as agriculture and plantations.

The high land capability class has $29.18 \%$ (1309402.02 ha) of the total typology area of the 5 island clusters. This ability class only exists in 3 typologies, namely Typology 1, 2 and 5, with a slight difference in the area from high to medium ability classes. Meanwhile, this class was found to be ideal for agricultural activities in built-up areas of low land capability class with $29.18 \%$ (1309402.02 ha) of the total typology area of 5 island clusters. However, it was only located on 3 typologies, the area with a difference from the area of high and medium ability classes.

\section{Land cover changes}

Analysis of land cover changes in Maluku Province is represented by 5 Typology of Island Cluster using time- series data on forest land cover from 2000 to 2018. Meanwhile, the land closure unit was classified as forest and non-forest land cover, with each cluster having a different unit. The forest loss for 18 years was 77102 ha with an average of $4283.4 \mathrm{ha} /$ year and also a \pm increase of 27199 ha with an average \pm 1511 ha/year. Furthermore, the loss of the most extensive non-forest land cover was \pm 154699 with an average of \pm 8594 ha. The highest increase in non-forest areas belonged to consecutive agricultural land of 170722 ha with an average of \pm $8594.55 \mathrm{ha} /$ year, Shrubs \pm 96180 ha with an average of \pm 5343 ha/year, and the \pm 85853 ha with an average of \pm $4770 \mathrm{ha} /$ year. Therefore, the total land closure losses from 2000 to 2018 were \pm 422805 ha with an average \pm $23489.06 \mathrm{ha} /$ year.

The most considerable change in forest land cover to non-forest was found in the bush/shrubs of 53347 ha $(69 \%)$ or an average \pm 2963.71 ha/year. This value was significantly high when compared with the forest area in Maluku Province which consists of small islands. Meanwhile, forest loss on small islands is very risky due to the functions of the forest. Briguglio (1995), stated that small islands have environmental problems that generally occur such as land degradation and biodiversity loss, the remoteness of the mainland, and world markets, and high exposure to natural disasters. These problems are further facilitated by population growth and urbanization. Moreover, there are changes in the environment due to transformation in time and basic needs such as clothing, food, and housing.

The conversion of forest land to the second-largest nonforest was on the agricultural land cover of 13074 (17\%) with an average of $\pm 726.33 \mathrm{ha}$ /year. This shows that the provision of food is to be considered by the government. When the government refuses to meet these basic needs, the community search for an accessible alternative, namely forest land that is auspicious for agricultural businesses due to a high fertility rate. Therefore, forest areas are a system that responds to challenges related to human interests (Thakur et al. 2020; Tuffour-Mills 2020).

Table 1. Table of distribution of Land Capability expressed in percent of the unit area in five typologies of island groups in Maluku Province, Indonesia

\begin{tabular}{|c|c|c|c|c|c|c|c|c|}
\hline \multirow{2}{*}{ Cluster } & \multicolumn{2}{|l|}{ Low } & \multicolumn{2}{|l|}{ Medium } & \multicolumn{2}{|l|}{ High } & \multirow{2}{*}{ Total } & \multirow{2}{*}{ Percent } \\
\hline & Comprehensive & Percent & Comprehensive & Percent & Comprehensive & Percent & & \\
\hline 1 & 912107.57 & 31.27 & 961775.85 & 32.98 & 1042656.86 & 35.75 & 2916540.28 & 65.00 \\
\hline 2 & 496701.92 & 54.89 & 250418.87 & 27.67 & 157780.63 & 17.44 & 904901.42 & 20.17 \\
\hline 3 & 56493.56 & 54.63 & 46924.82 & 45.37 & & & 103418.38 & 2.31 \\
\hline 4 & 151868.97 & 72.13 & 58681.78 & 27.87 & & & 210550.75 & 4.69 \\
\hline 5 & 90991.93 & 25.91 & 151287.93 & 43.07 & 108964.53 & 31.02 & 351244.39 & 7.83 \\
\hline Total & 1708163.95 & 38.07 & 1469089.25 & 32.74 & 1309402.02 & 29.18 & 4486655.22 & 100.00 \\
\hline
\end{tabular}




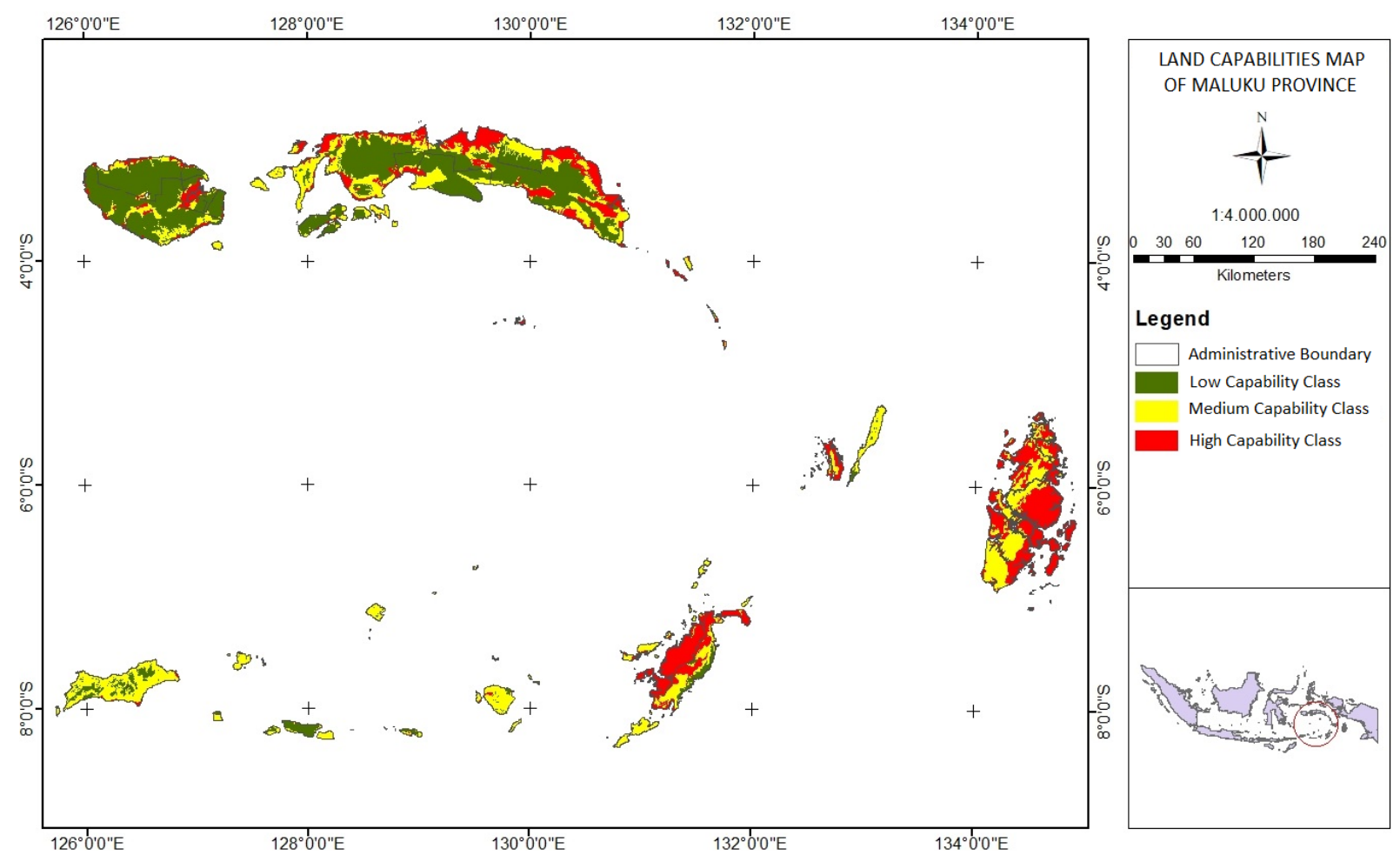

Figure 2. Land Capability Class on 5 Island Cluster Typologies

The total forest cover area lost over \pm 18 years was $77102 \mathrm{ha}$ or $4283.4 \mathrm{ha} / \mathrm{year}$. This value is of great concern because of the Maluku Provincial Island Group's typology condition, which is composed of a group of small islands that are vulnerable to global changes, especially impacts on climate change. These islands have distinctive characteristics and high susceptibility to degradation due to size and geographical isolation (Polido et al. 2014). Meanwhile, Lamarque et al. (2011) stated that forests provide guarantees for several ecosystem services such as the provision of raw materials for furniture, local, and global climates regulation weather buffers, regulating hydrological cycles, and protecting watersheds. This study showed that the conversion of forest land to built-land was very high at 993 ha, surpassing the other clusters. Moreover, the pressure of housing needs is one of the factors of forest degradation (Chase et al. 1999; Mabasa and Makhubele 2016; Addo-Fordjour and Ankomah 2017).

Furthermore, the lost or degraded land cover area was \pm 422805 ha with an average degradation/loss of \pm 23489.06 ha/year. This value was relatively high because the area comprises small islands vulnerable to global environmental changes. Meanwhile, the rate of land loss is to be minimized to prevent worse land degradation, since high vulnerability contributes to global environmental disturbances, such as climate change. Therefore, the solution is to ensure forest cover at an appropriate level to prevent/ mitigate global disasters due to climate change.

\section{Spatial trend analysis}

Spatial Trend analysis was conducted to determine the tendency of change in land cover due to human activities. This analysis was carried out in by measuring land changes at two different temporal regimes viz. 2000 and 2018, and the results showed the five levels of changes in forest land cover to non-forest land cover ranging from very low (red) to very high (purple) as shown in Figure 3. The response provided the relationship trend between the loss of forest land cover to non-forest ones for 18 years for the 5 topologies of the Island Cluster. Meanwhile, each typology provided a different response dependent on the rate of the forest land changes as shown in the color degradation change, from green to dark brown and wind direction.

The spatial trend results showed different tendencies in 5 typologies of island clusters, namely Typology 1 (a) and 5 (e). The changes in forest cover to non-forest towards the Northwest are described in the degradation of yellow to Purple. The results showed forest degradation in subdistricts of southern Buru Island (Typology 1) and subdistricts in the surrounding of Ambon Island. Furthermore, the Typology 2 (b) showed the direction of different Spatial Trends changes towards the Northeast. This change of forest land cover to non-forest leads to sub-districts in West Seram district, while the Typology 3 (c) and 4 (d) show different spatial trend directions. Typology 3 leads to the East which consists of the North Seram District and Typology 4 leads to the West in Amaha District, Central Maluku Regency. This analysis is shown to describe the spatio-temporal pattern of land cover change. 


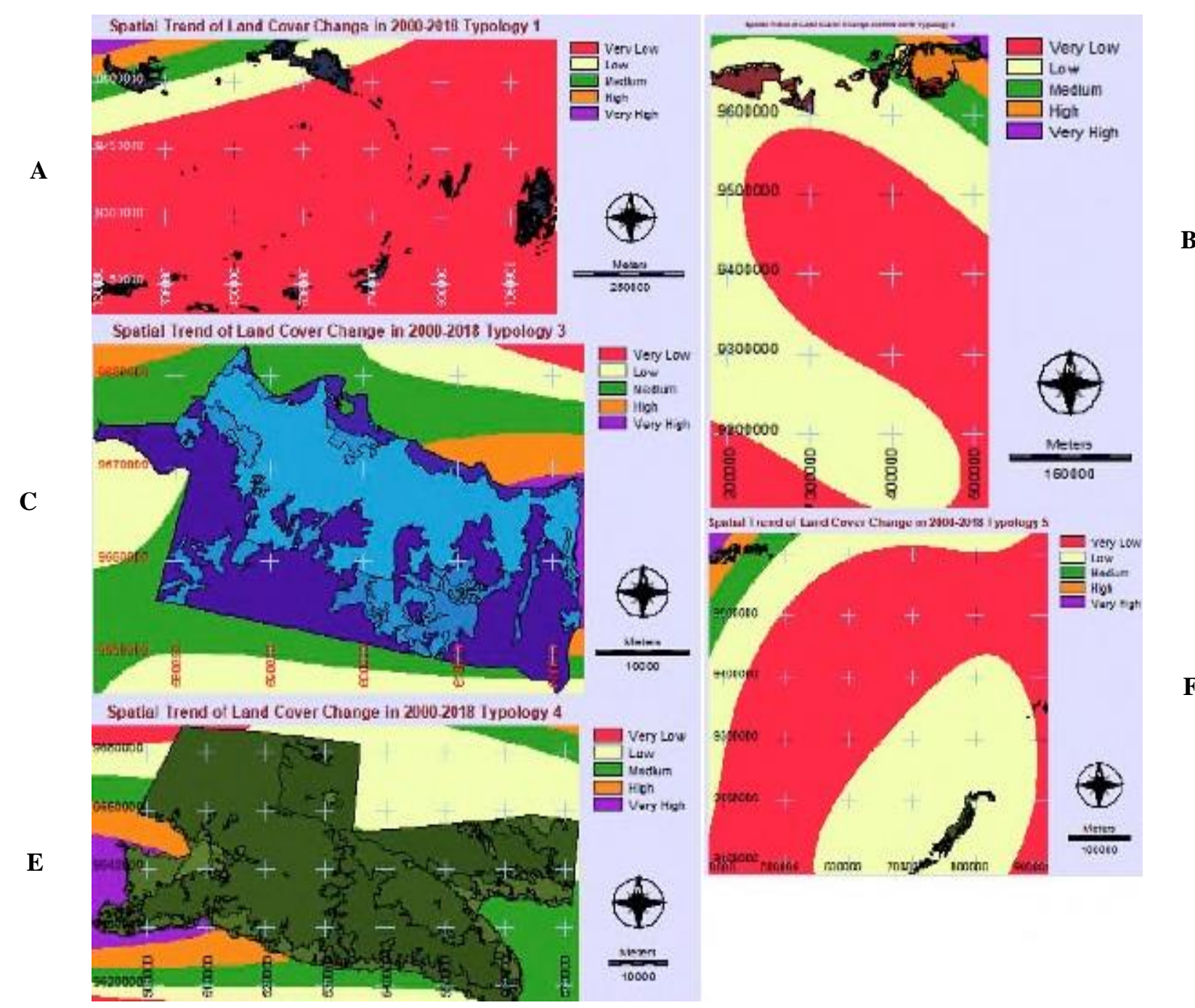

Figure 3. Spatial trend typology 5 island clusters. A. Typologi 1, b. Typologi 2, C. Typologi 3, D. Typologi 4, E. Typologi 5.

\section{Land use directives in $\mathbf{5}$ island cluster typology}

Land resource planning (land-use planning) is a tool to achieve sustainable and efficient use of resources with biophysical and socio-economical dimensions. This planning aims to support decision-makers and land users in selecting and practicing the use that best meets the community needs, while maintaining natural resources and ecosystem services for current and future generations. Moreover, this definition meets the common concept of sustainable development as stated by Lourenço et al. (2020). The analysis of 5 typologies of island clusters provides diverse information, namely, different land capability classes in each typology, changes in forest and non-forest land cover that affect the management of natural resources, and spatial trend analysis that helps manage land change trends (forest and non-forest). Based on government administration, the provincial government has set the direction of spatial planning for the province as stated in the Maluku Provincial Regulation Number 16 of 2013 concerning the spatial plan of the province from 2013 to 2033. The Regional Spatial Plan (RTRW) No.16 of 2013 has regulated several matters concerning land use that lead to sustainable natural resources management (Bappeda 2013). Meanwhile, article 80 regulates the directive of zoning regulations for Forest Production as follows: 1) the environmental function of forest areas for regional ecosystems balance, 2) controlling forestry resources to meet long-term needs. Furthermore, article 76, point 2, regulates directive of zoning regulations for Water Absorption Area as follows: a) to provide sufficient space in a particular area for rainwater absorption to protect the subordinate and the area concerned, b) to rehabilitate the increasingly dense surrounding area to control and restore its function c) to build an area that accommodates various development activities considering the land suitability.

Considering the bio-physical and socio-economic conditions, the results of the 5 typologies of the island group and the direction of space used in the RTRW showed that there is high risk due to thousands of small islands when the planning process of land use (forest) is not carried out properly. Therefore, some direction scenario plan management and utilization of natural resources in 5 Typology Island Cluster are given as follows: 


\section{Typology 1}

It has high, medium, and low land capability classes while witnessing the most extensive loss of forest and nonforest land cover and spatial trend analysis shows the potential forest resources tend to decline. Meanwhile, Typology with high ability classes is not suitable for the utilization of forest resources in form of wood. This typology is more suitable for utilizing non-timber forest products and services, especially water resources, germplasm protection, ecotourism, agroforestry (Dusun), and Health. When it is used for wood harvesting activities, it is necessary to observe a proper silviculture system, environmentally friendly, and strict supervision to prevent damage that exceeds the limits of environmental recovery tolerance. Meanwhile, Typology 1 with medium to low land capability land use directives are carried out by considering the potential of available natural resources (forests), clear and measurable utilization plans, such as timber harvesting activities carried out by private and government organizations. Furthermore, non-forestry activities such as agriculture are carried by considering the principles of ecosystem sustainability.

\section{Typology 2}

This is similar to Typology 1 and it has three classes of land capability. This typology has a percentage of the area of high land capability greater than the typology with $54 \%$. It should get serious attention to forest land use planning. In this class, the land-use scenario leads to forest services and non-timber products. Meanwhile, timber utilization is at high risk because the area is more dominated by rich topography, high rainfall, and a decrease in forest cover loss, especially bushland cover (22083 ha). This value is high when compared to typology 1 , which was losing forest to shrubs.

\section{Typology 3}

This typology has two classes of land ability, namely, high, and medium. The high capability land cover area is approximately half of the area, with a loss of $\pm 8 \%$. Land use directives in this typology are only for non-timber forest products and environmental services. The direction of forest resource utilization (wood) requires serious attention. In terms of planning, the environmentally friendly silviculture system and supervision are carried out maximally to maintain sustainable forest resources in the future. Moreover, pressure on the conversion of forest areas to awakening land requires special attention from the local government, since it causes deforestation.

\section{Typology 4}

This typology is similar to typology 3 , with only two classes of land ability, viz. high and medium. Furthermore, this typology is extreme because $\pm 72.13 \%$ are in the high land capability class and $27.87 \%$ in the medium ability class. This typology is dominated by forest land cover \pm $82 \%$ of the area. Therefore, the activities that lead to forest degradation become an essential priority. This typology scenario is almost the same as typology 3 that is directed to the utilization of forest services and non-timber forest products because most of the area is dominated by high levels of land ability. Although forests cover the largest area of typology, forest concessions are not recommended here.

\section{Typology 5}

This typology is unique because the forest cover area is $\pm 8 \%$ of the Island Cluster typology and it has 3 land capability classes. Moreover, forest covers $\pm 50 \%$ of the typology area, therefore, the conversion of forest land to non-forest is relatively high. This typology has a medium land capability class higher than the other two classes. In this typology, the land-use scenarios are directed towards non-timber forest products and services, while using natural resources is directed to non-forest areas such as agricultural lands. However, forest land use directives for timber harvesting are not recommended because of the small typology of the island cluster's total area.

In conclusion, the preparation of the scenario for the direction of forest land use in Maluku Province needs to consider the aspects of spatial trend and carrying capacity or capability class derived from the biophysical aspects of the area. In addition, information on the changes in the trend of spatial, forest, and land use is very crucial in determining the types of forest concessions to be carried out. Generally, the highest land capability classes were found in the sub-districts of Aru and Southwest Maluku Regency. The high spatial trend was found in typology 3 which is in the sub-districts of North Seram Kobi and North East Seram Seti/Central Maluku District, while the low trend was found in typology 1 in the sub-districts of South Buru and West Seram districts. Furthermore, the widest forest land use scenario for intensive forestry is in several sub-districts in Aru, West Southeast Maluku, and Parts of Central Maluku Regency and Eastern Seram covering an area of 1151621 ha, which generally belong to typology 1. Therefore, the area for moderate forestry business was found to be $\pm 1171746 \mathrm{Ha}$ in the sub-districts of West Southeast Maluku, Aru, West and East Seram, and Buru Island.

\section{ACKNOWLEDGEMENTS}

This study is part of a dissertation funded by the General Directorate of Higher Education (DIKTI), Indonesia,

\section{REFERENCES}

Addo-Fordjour P, Ankomah F. 2017. Patterns and drivers of forest land cover changes in tropical semi-deciduous forests in Ghana. J Land Use Sci 12 (1): 71-86. DOI: 10.1080/1747423X.2016.1241313.

AL-Taani A, Al-Husban Y, Farhan I. 2021. Land suitability evaluation for agricultural use using GIS and remote sensing techniques: The case study of Ma'an Governorate, Jordan. Egypt J Rem Sens Space Sci 24: 109-117. DOI: 10.1016/j.ejrs.2020.01.001

Atalay I. 2016. A New Approach to the Land Capability Classification: Case Study of Turkey. Procedia Environ Sci 32: 264-274. DOI: 10.1016/j.proenv.2016.03.031. 
Baja S. 2012. Land Use in Regional Development with Spatial Approach and Application. Yogyakarta. [Indonesian]

BAPPEDA. 2013.Regional Spatial Plan of Maluku Province 2007-2037. Provincial Government of Maluku, Ambon. [Indonesian]

Bottero M, Comino E, Duriavig M, Ferretti V, Pomarico S. 2013. The application of a Multicriteria Spatial Decision Support System (MCSDSS) for the assessment of biodiversity conservation in the Province of Varese (Italy). Land Use Pol 30: 730-738. DOI: 10.1016/j.landusepol.2012.05.015.

Briguglio L. 1995. Small island developing states and their economic vulnerabilities. World Dev 23(9): 1615-1632. DOI: 10.1016/0305 $750 \mathrm{X}(95) 00065-\mathrm{K}$.

Chase TN. Pielke RASr, Kittel TGF, Nemani RR, Running SW. 1999. Simulated impacts of historical land cover changes on global climate in northern winter. Clim Dyn 16: 93-105. DOI $10.1007 / \mathrm{s} 003820050007$

Chen IC, Hill JK, Ohlemller R, Roy DB, Thomas CD. 2011. Rapid range shifts of species associated with high levels of climate warming. Science 333: 1024-1026. DOI: 10.1126/science.1206432.

Eastman JR. 2020. TerrSet 2020. Geospatial Monitoring and Modeling System. Manual. Clarks Labs. www.clarklabs.org.

FAO 2015. Global Forest Resources Assessment 2015. Food and Agriculture Organization of the United Nations, Rome.

Farhan AR, Lim S. 2011. Resilience assessment on coastline changes and urban settlements: A case study in Seribu Islands, Indonesia. Ocean

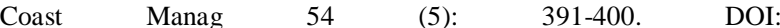
10.1016/j.ocecoaman.2010.12.003.

Gibson J. 2018. Forest Loss and Economic Inequality in the Solomon Islands: Using Small-Area Estimation to Link Environmental Change to Welfare Outcomes. Ecol Econ 148: 66-76. DOI 10.1016/j.ecolecon. 2018.02.012.

Kazemi H, Akinci H. 2018. A land use suitability model for rainfed farming by Multi-criteria Decision-making Analysis (MCDA) and Geographic Information System (GIS). Ecol Eng 116: 1-6. DOI: 10.1016/j.ecoleng.2018.02.021.

Köhl M, Lasco R, Cifuentes M, Jonsson Ö, Korhonen KT, Mundhenk P, et al. 2015. Change in forest production, biomass and carbon, results from the 2015 UN Global Forest Resources Assessment. For Ecol Manag 352: 21-34. DOI: 10.1016/j.foreco.2015.05.036.

Khawaldah HA. 2016. A Prediction of Future Land Use/Land Cover in Amman Area Using GIS-Based Markov Model and Remote Sensing. J Geogr Inf Syst 8: 412-427. DOI: 10.4236/jgis.2016.83035.

Lamarque P, Quétier F, Lavorel S. 2011. The diversity of the ecosystem services concept and its implications for their assessment and management. $\mathrm{C}$ R Biol 334: 441-449. DOI 10.1016/j.crvi.2010.11.007

Lindenmayer DB, Franklin JF, Lõhmus A, Baker SC, Bauhus J, Beese W, et al. 2012. A major shift to the retention approach for forestry can help resolve some global forest sustainability issues. Conserv Lett 5: 421-431. DOI: $10.1111 / \mathrm{j} .1755-263 X .2012 .00257$

Lourenço IB, Guimara es LF, Alves MB, Miguez MG 2020. Land as a sustainable resource in city planning: The use of open spaces and drainage systems to structure environmental and urban needs. J Cleaner Prod 276: 123096. DOI: 10.1016/j.jclepro.2020.123096.

Mabasa MA, Makhubele JC. 2016. Impact of deforestation on sustainable livelihoods in low-resourced areas of Thulamela Local Municipality:
Implications for practice. J Hum Eco 55: 173-182. DOI: 10.1080/09709274.2016.11907021.

Mazahreh S, Bsoul M, Hamoor DA. 2019. GIS approach for assessment of land suitability for different land use alternatives in semi arid environment in Jordan: Case study (Al Gadeer Alabyad-Mafraq). Inf Process Agric 6(1): 91-108. DOI: 10.1016/j.inpa.2018.08.004.

Mori AS. 2011. Ecosystem management based on natural disturbances: Hierarchical context and non-equilibrium paradigm. J Appl Ecol 48: 280-292. DOI:10.1111/j.1365-2664.2010.01956.x.

Oettel J, Lapin K. 2020. Linking forest management and biodiversity indicators to strengthen sustainable forest management in Europe. Ecol Indic 122: 107275. DOI: 10.1016/j.ecolind.2020.107275.

Pascual A. 2021. Multi-objective forest planning at tree-level combining mixed-integer programming and airborne laser scanning, For Ecol Manag 483: 118714. DOI: 10.1016/j.foreco.2020.118714.

Polido A, Joāo E, Ramos TB. 2014. Sustainability approaches and strategic environmental assessment in small islands: An integrative review. Oceana Coast Manag 96 (8): 138-148. DOI: 10.1016/j.ocecoaman.2014.05.005.

Rocha JSM, Kurtz SMJM. 2001. Manual de manejo integrado de bacias hidrográficas. $4^{\text {th }}$ Ed. Santa Maria: UFSM/CCR [in Portuguese].

Stanturf JA, Palik BJ, Dumroese RK. 2014. Contemporary forest restoration, a review emphasizing function. For Ecol Manag 331: 292-323. DOI: 10.1016/j.foreco.2014.07.029.

Sun T, Feng Z, Yang Y, Lin Y, Wu Y. 2018. Research on land resource carrying capacity: progress and prospects. J Res Ecol 9 (4): 331-340. DOI: $10.5814 /$ j.issn. $1674-764 x .2018 .04 .001$

Tarawally M, Wenbo X, Weiming H, Mushore TD, Kursah MB. 2019. Land use/land cover change evaluation using land change modeller: A comparative analysis between two main cities in Sierra Leone. Remote Sens Appl Soc Environ 16: 100262. DOI: 10.1016/j.rsase.2019.100262.

Thakur TK, Patel DK, Bijalwan A, Dobriyal MJ, Kumar A, Thakur A, et al. 2020. Land use land cover change detection through geospatial analysis in an Indian Biosphere Reserve. Trees For People 2:100018. DOI: $10.1016 /$ j.tfp. 2020.100018 .

Tudoran GM, Zotta M. 2020. Adapting the planning and management of Norway spruce forests in mountain areas of Romania to environmental conditions including climate change. Sci Total Environ 698: 133761. DOI: 10.1016/j.scitotenv.2019.133761.

Tuffour-Mills D, Antwi-Agyei P, Addo-Fordjour P. 2020. Trends and drivers of land cover changes in a tropical urban forest in Ghana. Trees For People 2: 100040. DOI: 10.1016/j.tfp.2020.100040.

Veldkamp A, Lambin EF. 2001. Predicting land-use change. Agric Ecosyst Environ 85: 1-6. DOI: 10.1016/S0167-8809(01)00199-2.

Zari MP. 2014. Ecosystem Services Analysis in Response to Biodiversity Loss Caused by the Built Environment, S.A.P.I.EN.S. http://journals.openedition.org/sapiens/1684

Zekâi Ş. 2017. Innovative Trend Methodologies in Science and Engineering. Springer International Publishing AG. DOI: 10.1007/978-3-319-52338-5.

Zhang YJ, Li AJ, Fung T. 2012. Using GIS and multi-criteria decision analysis for conflict resolution in land use planning. Proc Environ Sci 13: 2264-2273. DOI: 10.1016/j.proenv.2012.01.215. 